\title{
STUDY AWAL KARAKTERISASI SENSOR WARNA TC3200 UNTUK MENENTUKAN KADAR KAFEIN PADA KOPI
}

\author{
Heriyanti', Samsidar ${ }^{2}$, Iful Amri', Jesi Pebralia ${ }^{2}$, Rustan $^{2}$, Linda Handayani ${ }^{2}$, Mardian Peslinof $^{2}$ \\ Desi Ayundari ${ }^{2}$, Sutrisno ${ }^{1 *}$ \\ ${ }^{1}$ Program Studi Kimia, Fakultas Sains dan Teknologi, Universitas Jambi,Jl. Jambi-Muara Bulian, Km.15, Kab. Muaro Jambi, Indonesia \\ ${ }^{2}$ Program Studi Fisika, Fakultas Sains dan Teknologi, Universitas Jambi,Jl. Jambi-Muara Bulian, Km.15, Kab. Muaro Jambi, Indonesia \\ *e-mail: herasutrisno@unja.ac.id
}

\begin{abstract}
ABSTRAK
Pengukuran kadar kafein saat ini dibutuhkan agar penggunaan/konsumsi kopi sesui dengan dosis yang dibutuhkan, akan tetapi, sulitnya karakterisasi dan uji kimia dalam penentuan kadar kafein menjadi hambatan untuk mengetahui dosis kafein secara cepat dan tepat. Pada penelitian ini telah dilakukan karakterisasi sensor warna TC3200 sebagai studi awal rangkaian pembuatan alat ukur kafein berbasis sensor. Sampel yang digunakan adalah kopi Liberika, Arabika dan Robusta yang berasal dari Provinsi Jambi. Preparasi sampel dilakukan dengan proses roasting pada suhu $180^{\circ} \mathrm{C}$ dan pada saat proses berjalan pengambilan sampel secara real time pada $(t=38-45 \mathrm{~s})$, hasil preparasi sampel dilakukan uji UV-Vis untuk mengetahui konsentrasi kandungan kadar kafein. Selanjutnya karakterisasi sensor warna TC3200 dilakukan untuk mengetahui nilai RGB (Red, Green, Blue) dari masing - masing sampel kopi. Hasil penelitian didapatkan nilai kadar kafein dari pengukuran UV-Vis yang akan menjadi database sensor, dan hasil karakterisasi sensor warna TC3200 pada kopi Liberika, Arabika dan Robusta secara kuantitatif didapatkan tingkat kevalidan data masing - masing 80\%, 60\% dan 70\% dan analisis kualitatif bahwa sensor dapat digunakan untuk menetukan kadar kafein pada kopi dengan tingkat kematangan atau waktu roasting kopi yang berbeda.
\end{abstract}

Kata Kunci: Sensor Warna; Kafein; Kopi.

\begin{abstract}
[Title: A Study of Color Sensor TCS3200 for Determining Caffeine Content of Coffee] Measurement of caffeine levels of coffee is currently needed so that the consumption of coffee is in accordance with the required dose, but the difficulty of characterization and chemical tests in determining caffeine levels is an obstacle to knowing the dose of caffeine quickly and accurately. In this study, calibration of the TC3200 color sensor was carried out as an initial study of a series of sensor-based caffeine measuring instruments, the samples used were Liberika, Arabica and Robusta coffee samples from Jambi Province. Sample preparation was carried out by roasting at $180 \mathrm{oC}$ and during the real time sampling process at $(t=38-45 s)$, the results of sample preparation were subjected to a UV-Vis test to determine the caffeine content. Furthermore, the calibration of the TC3200 color sensor is carried out to determine the RGB value of each coffee sample. The results showed that the value of caffeine content from the UV-Vismeasurement which will be the sensor database, and the results of the calibration of the TC3200 color sensor on Liberika, Arabica and Robusta coffee quantitatively obtained data validity levels of 80\%, 60\% and $70 \%$ respectively and qualitative analysis that the sensor can be used to determining caffeine content of coffee with different time roasting.
\end{abstract}

Keywords: Color sensor; Caffeine; Coffee.

\section{PENDAHULUAN}

Produksi kopi di Indonesia menunjukkan kenaikan dari tahun ke tahun, peningkatannya sebesar 18,76 \% terjadi dari tahun 2014 - 2018 (Direktorat Jenderal Perkebunan, 2019). Sekitar $70 \%$ jenis kopi yang diproduksi dan dikomersialkan adalah kopi jenis arabika, lalu kopi robusta sebanyak $28 \%$, dan 2\% adalah jenis kopi liberika dan excelsa (Farah, 2012). Biji kopi arabica berbentuk bulat lonjong memanjang, biji kopi robusta cenderung berbentuk lingkaran padat, dan biji kopi liberika terdapat satu ujung mengerucut di salah satu ujung keping (Arboleda, 2019).

Kualitas kopi sangat ditentukan oleh proses pengolahan terutama pada proses roasting/sangrai, untuk itu perlu adanya informasi terkait waktu dan suhu yang digunakan agar dapat dihasilkan kualitas 
kopi baik. Pengukuran kualitas kopi telah dilakukan pada variasi suhu roasting (Craing., 2018).

Sementara itu, untuk menganalisis kandungan kafein pada kopi dapat dilakukan dengan menggunakan UV-Vis (Arwangga, A,dkk, 2016) dimana kadar kafein kopi murni yg telah dilakukan proses oven $\left(100^{\circ} \mathrm{C} \mathrm{t}=2 \mathrm{Jam}\right)$ lebih tinggi dari kadar kafein kopi mentah atau yang belum disangrai. Pengkuran kadar kafein menggunakan UV-Vis dengan pelarut Aquades dan diklorometana diproleh koefisien serapan dan momen dipol transisi pada panjang gelombang 272nm dan 274,7nm (Belay, $\mathrm{dkk}, 2008)$.

Prediksi kandungan kadar kafein pada kopi telah dilakukan, diantaranya dengan metode Near Infrared Spectroskopi (NIR). Hasil uji kafein dengan menggunakan uji kimia dijadikan sebagai acuan penentuan kafein dengan NIR dan dihasilkan bahwa metode cepat menggunakan NIR dapat digunakan untuk menentukan kadar kafein (Rosita, R. dkk, 2016).

Sensor warna merupakan sensor yang bekerja dengan cara membaca nilai intensitas cahaya yang dibaca melalui matriks fotodioda. Setiap warna yang dipancarkan oleh LED memiliki panjang gelombang yang berbeda-beda sesuai dengan warna objek (Iwanto,2015), warna yang terdeteksi adalah warna dasar Read, Green, Blue (RGB) (Husni. N.,dkk, 2020). Pengunaan sensor warna telah banyak dilakukan diantaranya dengan pengukuran kandungan polifenol teh pada teh hijau (Jiang, H.,dkk, 2020) dengan cara mendeteksi perubahan warna dari informasi aroma teh, dari hasil penelitian bahwa sensor warna memiliki kelayakan dengan error 1,6\% sebagai alat deteksi kandungan polifenol pada teh. Penggunaan sensor warna juga telah dilakukan sebagai penentu kualitas kemurnian bensin (Putra, E. A., 2017), Kadar hara tanah sawa (Syam. S., 2017), Kandungan formalin pada ikan asin (Singgih, H., 2013). Pada penelitian ini akan dilakukan penentuan kadar kafein pada kopi Liberika, Arabika dan Robusta dengan menggunakan sensor warna, sebagai standar database kadar kafein pada sensor dilakukan uji UV-Vis pengukuran konsentrasi kadar kafein untuk berbagai jenis sampel dengan variasi waktu dan suhu roasting.

\section{METODE}

\section{Preparasi Sampel}

Sampel yang digunakan dalam pengkuran kadar kafein adalah jenis kopi liberika, Arabika dan Robusta yang telah di roasting pada suhu $180^{\circ} \mathrm{C}$, dan dilakukan pengambilan sampel secara real time, yaitu pada rentang waktu roasting berlangsung saat $\mathrm{t}=38$ $\mathrm{s}-45 \mathrm{~s}$ dengan suhu roasting $180^{\circ} \mathrm{C}$ masing-masing di dapat 10 variasi sampel untuk satu jenis kopi. Adapun variasi sampel dapat dilihat pada gambar 1, 2, dan 3 .

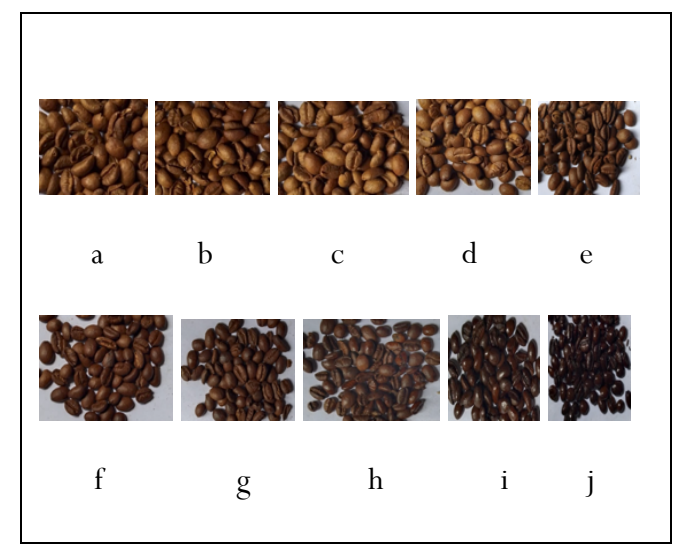

Gambar 1. Sampel kopi liberika dengan suhu roasting $180^{\circ} \mathrm{C}(\mathrm{t}=38 \mathrm{~s}-45 \mathrm{~s})$

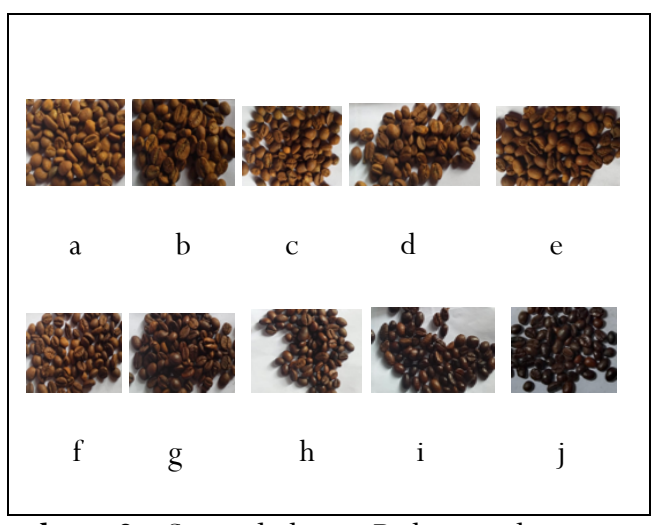

Gambar 2. Sampel kopi Robusta dengan suhu roasting $180^{\circ} \mathrm{C}(\mathrm{t}=38 \mathrm{~s}-45 \mathrm{~s})$

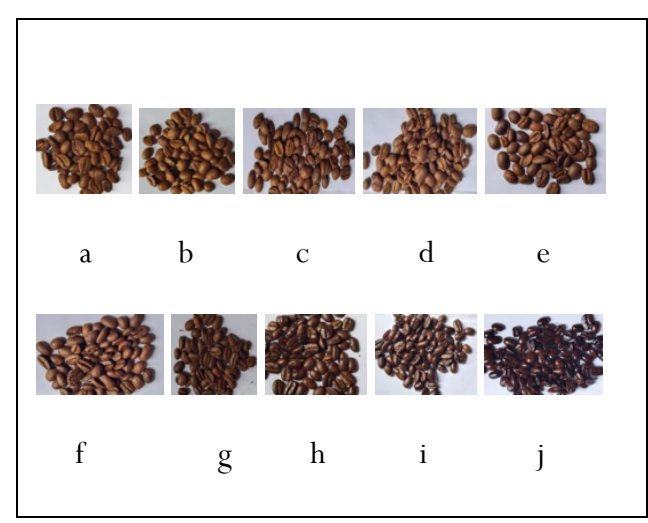

Gambar 3. Sampel kopi Arabika dengan suhu roasting $180^{\circ} \mathrm{C}(\mathrm{t}=38 \mathrm{~s}-45 \mathrm{~s})$

Setelah proses roasting selanjutnya dilanjutkan uji kimia untuk mengetahui kadar kafein, dalam hal ini pengujian dilakukan dengan menggunakan UVVis. Sebelum proses pengujian dilakukan, terlebih dahulu di lakukan preparasi sampel lanjut dengan cara menghaluskan sample (proses grinding) dan 
dilanjutkan dengan pembuatan larutan standar serta larutan masing-masing sampel.

Pembutan larutan standar dilakukan dengan pelarut akuades dan diklorometan, kosentrasi larutan masing-masing 1 ppm, 3 ppm, 5 ppm, 7 ppm dan 10 ppm.dalam pembuatan larutan digunakan sample standar 0,01gr kemudian dilarutkan dengan pelarut akuades $100 \mathrm{ml}$.

Untuk proses preparasi sampel kopi dilanjutkan dilaboratorium, penghalusan kopi hasil grinding dengan blender kemudian dilakukan pengayakan menggunakan saringan 250 mikron, masing-masing sampel disiapkan sebanyak $50 \mathrm{mg}$ dan dilarutkan dengan $25 \mathrm{ml}$ akuades serta diaduk dengan magnetic stirrer selama 1 jam kemudian disaring dengan filter glass. Sampel yang telah dipreparasi dicampur diklorometan perbandingan (25 ml:25ml) kemudian dilakukan kembali pengadukan magnetic stirrer selama 10 menit. Selanjutnya ekstrasi menggunakan corong pemisah dilakukan, sebanyak 4 kali pengulangan dan digunakan diklorometer setiap satu siklus. Setelah serangkaian preparasi maka larutan yang dihasilakn akan diuji dengan menggunakan Uv-Vis. Selain dilakukan pengujian kadar kafein dengan menggunakan Uv-Vis, terhadap sampel yang sama dilakukan pengukuran nilai RGB spesifikasi sensor TCS3200. Data hasil perekaman akan disesuikan dengan hasil pengukuran kada kafein, hal ini akan menjadi sumber data sensor yang nantinya akan digunakan untuk mengukur kadar kafein secara langsung.

\section{Perancangan Alat}

Modul sensor warna TCS230 dirancang untuk mengkonversi warana objek menjadi sebuah frekuensi yang akan diolah dan diterjemahkan oleh mikrokontroler, dalam hal ini sensor warna berperan mendeteksi warana kopi sesuai karakteristik dan kandungan kafein. Adapuun blok diagram rangkaian seperti pada gambar 4 .

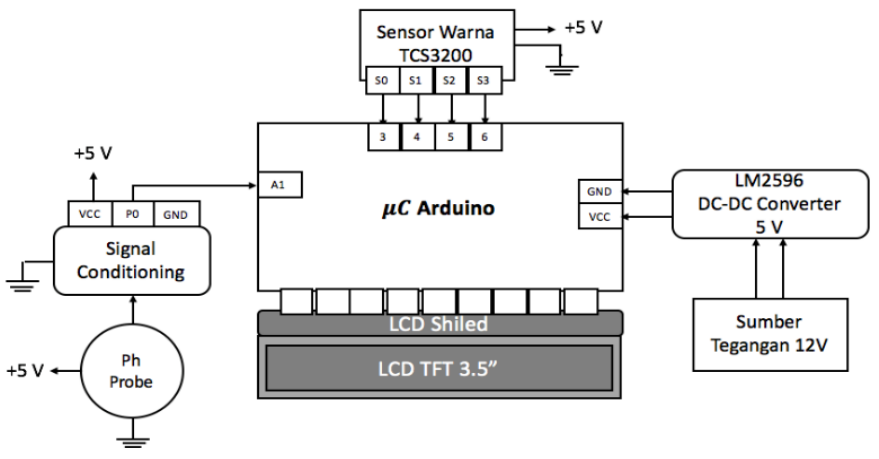

Gambar 4. Skema Alat Sensor Kadar Kafein

Mekanisme kerja sensor warana ketika kopi disinari LED, maka kopi akan memantulkan sinar LED tersebut dan akan tertangkap oleh photodiode, pantulan sinar tersebut memiliki panjang gelombang yang berbeda-beda hal ini sangat tergantung dengan warna kopi yang akan diukur. Panjang gelombang dan sinar LED yang dipantulkan oleh sampel kopi akan dibawa untuk mengaktifkan salah satu kelompok photodiode, selanjutnya S2 dan S3 (pada gambar 4) akan mengirimkan sinyal ke mikrokontroler untuk menginformasikan warna yang

dideteksi

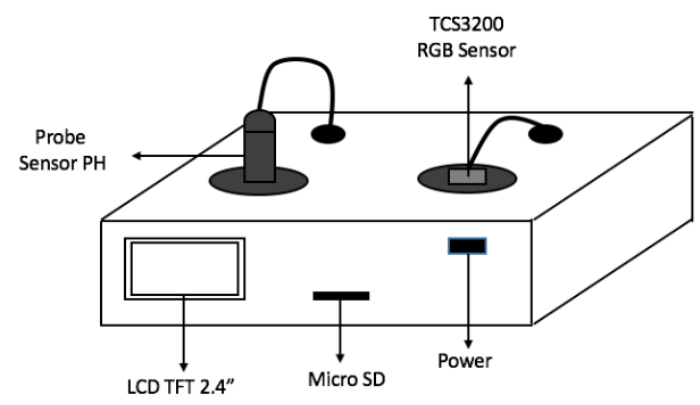

Gambar 5. Desain Prototipe Alat Pengukur Kadar Kafein 
Setelah diproses oleh mikrokontroler Arduino dan diterjemahkan oleh jenis warna maka data tersebut akan dibandingkan dengan database yang ada pada memory penyimpanan pada modul Micro SD, secara sederhana database yang ada pada kartu memori akan "dipanggil" terlebih dahulu selanjutknya disesuikan dengan hasil deteksi sensor maka akan diperoleh informasi kadar kafein kopi tersebut, dan hasil pembacaan akan ditampilkan pada LCD TFT.

\section{HASIL DAN PEMBAHASAN}

Sensor TCS3200 adalah sebuah sensor dengan nilai keluraan berupa data RGB. Akan tetapi, sensor ini masih memiliki kekurangan yaitu nilai RGB yang dihasilkan masih belum sesuai dengan nilai RGB pada software desain grafis. Oleh karena itu, untuk dapat menggunakannya, sensor TCS3200 perlu untuk dikarakterisasi.

Karakterisasi dilakukan untuk mengetahui nilai RGB yang dihasilkan oelh senso agar dapat digunakan untuk pengukuran kafein secara langsung. Selanjutnya hasil pengukuran dilakukan perbandingan dengan hasil pengujian kadar kafein dengan menggunakan UV-Vis. Plot ketepatan pengkuran akan menjadi standar kelayakan dari alat pengukur kadar kafein. Hasil karakteriasi Nilai RGB sensor TCS3200 ditunjukkan pada tabel 1 .

Tabel 1. Hasil karakteriasi Nilai RGB sensor TCS3200

\begin{tabular}{|llccc}
\hline \multirow{2}{*}{ Warna } & \multirow{2}{*}{ Definsi } & \multicolumn{3}{c}{ Kode } \\
\cline { 3 - 5 } & & R & G & B \\
\hline & Hitam & 163 & 172 & 118 \\
\hline & Coklat & 78 & 139 & 101 \\
\hline Kuning Tua & 17 & 36 & 50 \\
\hline Kuning & 17 & 22 & 42 \\
\hline & Merah & 22 & 84 & 62 \\
\hline & Pink & 25 & 102 & 50 \\
\hline Hijau & 92 & 48 & 63 \\
\hline & Hijau Muda & 41 & 32 & 60 \\
\hline Biru & 114 & 65 & 25 \\
\hline Biru Muda & 131 & 45 & 17 \\
\hline
\end{tabular}

Berdasarkan tabel 1, dapat dilihat bahwa nilai RGB yang diperoleh telah sesuai dengan yang diinginkan. Berdasarkan data tersebut tidak ada nilai R, G, dan B berada pada rentang 0-255. Dengan demikian, sensor TCS3200 meiliki performansi yang baik dalam menentukan warna.

Selanjutnya, setelah dilakukan karakterisasi terhadap sensor TCS3200, maka pengujian pengukuran level warna pada kopi dapat dilakukuan. Pengujian dilakukan terhadap 3 jenis sampel kopi, yaitu kopi liberika, arabika, dan robusta.

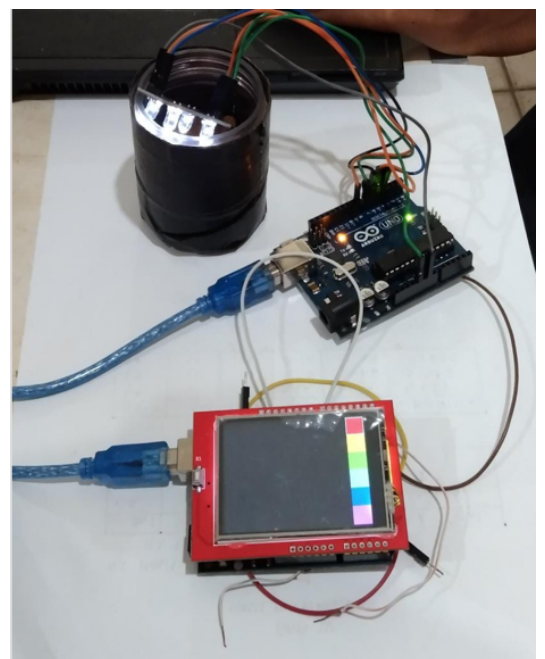

Gambar 5. Pengukuran kadar kafein dengan menggunakan sensor TC3200

Hasil pengukuran sensor warna TC3200 terhadap variasi sampel kopi Liberika dapat dilihat pada Tabel 2:

Tabel 2. Hasil Pengukuran Nilai RGB Kopi Liberika

\begin{tabular}{|c|c|c|c|c|}
\hline \multirow{2}{*}{$\begin{array}{c}\text { Sample } \\
\text { No. }\end{array}$} & \multicolumn{3}{|c|}{ Nilai RGB } & \multirow{2}{*}{$\begin{array}{l}\text { Kesimpulan } \\
\text { Pengukuran }\end{array}$} \\
\hline & $\mathbf{R}$ & $G$ & B & \\
\hline 1 & 70 & 130 & 124 & Valid \\
\hline 2 & 60 & 118 & 117 & Valid \\
\hline 3 & 63 & 128 & 125 & Valid \\
\hline 4 & 67 & 138 & 134 & Valid \\
\hline 5 & 82 & 168 & 155 & Valid \\
\hline 6 & 88 & 179 & 163 & Valid \\
\hline 7 & 94 & 180 & 156 & Valid \\
\hline 8 & 114 & 226 & 192 & Valid \\
\hline 9 & 137 & 253 & 204 & $\begin{array}{c}\text { Nilai RGB } \\
>250\end{array}$ \\
\hline 10 & 175 & 300 & 230 & $\begin{array}{c}\text { Nilai RGB } \\
>250\end{array}$ \\
\hline
\end{tabular}

Dari Tabel 2, hasil pengukuran RGB pada sampel kopi liberika didapatkan sebesar $80 \%$ hasil pengukuran dinyatakan valid karena masih berada pada tingkatan warna yang ada di database sensor warna TC3200, untuk sampel 9 dan 10 dinyatakan melewati ambang batas nilai RGB / RGB>250 hal ini dikarenakan warna hasil roasting yang suda sangat 
pekat/Hitam karena tingkat kematangan roasting yang melebihi dari normal. Hasil pengukuran nilai RGB pada sampel kopi Arabika juga dapat dilihat pada Tabel 3.

Tabel 3. Hasil Pengukuran Nilai RGB Kopi Arabika

\begin{tabular}{ccccc}
\hline $\begin{array}{c}\text { Sample } \\
\text { No. }\end{array}$ & \multicolumn{3}{c}{ Nilai RGB } & $\begin{array}{c}\text { Kesimpulan } \\
\text { Pengukuran }\end{array}$ \\
\cline { 2 - 4 } & $\mathbf{R}$ & $\mathbf{G}$ & $\mathbf{B}$ & Valid \\
\hline 1 & 83 & 166 & 148 & Valid \\
\hline 2 & 85 & 147 & 124 & Valid \\
\hline 3 & 140 & 245 & 223 & Valid \\
\hline 4 & 132 & 245 & 232 & Valid \\
\hline 5 & 90 & 185 & 167 & Valid \\
\hline 6 & 132 & 280 & 242 & $\begin{array}{c}\text { Nilai RGB } \\
>250\end{array}$ \\
\hline 7 & 146 & 289 & 249 & $\begin{array}{c}\text { Nilai RGB } \\
>250\end{array}$ \\
\hline 8 & 182 & 346 & 280 & $\begin{array}{c}\text { Nilai RGB } \\
>250\end{array}$ \\
\hline 9 & 204 & 380 & 302 & $\begin{array}{c}\text { Nilai RGB } \\
>250\end{array}$ \\
\hline 10 & 203 & 353 & 277 &
\end{tabular}

Tabel 7 merupalan hasil pengukuran nilai RGB pada kopi Arabika dengan tingkat ke validan data sebesar $60 \%$ dari 10 sampel yang tersedia, sebanyak 4 sampel yaitu sampel 7,8,9 dan 10 mempunyai nilai RGB besar dari 250, banyaknya sampel arabika yang memiliki nila $\mathrm{RGB}>250$ dikarenakan sample kopi liberika mempunyai ukuran biji yang lebih kecil dibandingkan dengan sample kopi lainya, sehingga apabila dilakukan roasting dengan perlakuan sama maka akan didapatkan lebih banyak sample dengan tingkat kematangan melewati batas normal/hitam pekat.

Tabel 4. Hasil Pengukuran Nilai RGB Kopi Robusta

\begin{tabular}{|c|c|c|c|c|}
\hline \multirow{2}{*}{$\begin{array}{c}\text { Sample } \\
\text { No. }\end{array}$} & \multicolumn{3}{|c|}{ Nilai RGB } & \multirow{2}{*}{$\begin{array}{l}\text { Kesimpulan } \\
\text { Pengukuran }\end{array}$} \\
\hline & $\mathbf{R}$ & $G$ & B & \\
\hline 1 & 63 & 127 & 125 & Valid \\
\hline 2 & 67 & 131 & 128 & Valid \\
\hline 3 & 75 & 148 & 142 & Valid \\
\hline 4 & 82 & 165 & 150 & Valid \\
\hline 5 & 91 & 181 & 167 & Valid \\
\hline 6 & 117 & 232 & 203 & Valid \\
\hline 7 & 116 & 229 & 198 & Valid \\
\hline 8 & 255 & 460 & 359 & $\begin{array}{c}\text { Nilai RGB } \\
>250\end{array}$ \\
\hline 9 & 182 & 332 & 263 & $\begin{array}{c}\text { Nilai RGB } \\
>250\end{array}$ \\
\hline 10 & 180 & 324 & 258 & $\begin{array}{c}\text { Nilai RGB } \\
>250\end{array}$ \\
\hline
\end{tabular}

Nilai RGB pada sampel kopi Robusta seperti pada Tabel 3, didapatkan hasil 70\% dari sampel dinyatakan valid dan 30\% dinyatakan memiliki nilai RGB $>250$.

\section{Hasil Pengukuran UV-Vis}

Hasil pengukuran nilai UV-Vis pada kopi liberika dapat dilihat pada tabel berikut

Tabel 5. Kadar Kafein Kopi Liberika

\begin{tabular}{cc}
\hline Sample & $\begin{array}{c}\text { Konsentrasi Kadar Kafein } \\
(\mathbf{p p m})\end{array}$ \\
\hline Sampel 1 & 10,72574257 \\
\hline Sampel 2 & 10,79009901 \\
\hline Sampel 3 & 10,22079208 \\
\hline Sampel 4 & 8,34950495 \\
\hline Sampel 5 & 8,924752475 \\
\hline Sampel 6 & 11,3950495 \\
\hline Sampel 7 & 9,506930693 \\
\hline Sampel 8 & 12,7950495 \\
\hline Sampel 9 & 16,41089109 \\
\hline Sampel 10 & 28,74356436 \\
\hline
\end{tabular}

Kadar kafein pada kopi liberika pada pemanasan suhu $180^{\circ}$ untuk sampel 1 sampai 3 cendrung memiliki kadar kafein relatif sama dan mengalami konsintensi kenaikan pada sampel 4 sampai dengan sample 10. ketidak konsitenan kadar kafein sampel 1 sd 3 diakibatkan kurang meratanya tingkat kematangan kopi, ini terlihat dengan tingkat warna yang justru lebih gelap dibandingkan dengan sampel 4. Secara keseluruhan pada kopi liberika kadar kafein mengalami peningkatan seiring dengan peningkatan kematangan kopi yang dicirikan semakin pekatnya warna hasil roasting. Untuk kadar kafein pada kopi arabika seperti pada tabel 6 berikut.

Tabel 6. Kadar Kafein Kopi Arabika

\begin{tabular}{cc}
\hline Sample & $\begin{array}{c}\text { Konsentrasi Kadar Kafein } \\
(\mathbf{p p m})\end{array}$ \\
\hline Sampel 1 & 8,655445545 \\
\hline Sampel 2 & 19,20792079 \\
\hline Sampel 3 & 22,35445545 \\
\hline Sampel 4 & 16,11485149 \\
\hline Sampel 5 & 31,36930693 \\
\hline Sampel 6 & 11,02079208 \\
\hline Sampel 7 & 8,607920792 \\
\hline Sampel 8 & 6,817821782 \\
\hline Sampel 9 & 6,432673267 \\
\hline Sampel 10 & 8,869306931 \\
\hline
\end{tabular}

Karakteristik kadar kafein pada kopi arabika mengalami fluktuasi, namun secara umum pada tingkat kematangan sempurna seperti sample 6 
sampai 10 memiliki kadar kafein lebih rendah dari tingkat kematangan medium seperti pada sampel 1 sampai 5. Selanjutnya karakteristik kadar kafein untuk kopi robusta dapat dilihat pada table 7 .

Tabel 7. Kadar Kafein Kopi Robusta

\begin{tabular}{cc}
\hline Sample & $\begin{array}{c}\text { Konsentrasi Kadar Kafein } \\
(\mathbf{p p m})\end{array}$ \\
\hline Sampel 1 & 80,26930693 \\
\hline Sampel 2 & 33,18613861 \\
\hline Sampel 3 & 38,14851485 \\
\hline Sampel 4 & 168,1663366 \\
\hline Sampel 5 & 87,98019802 \\
\hline Sampel 6 & 98,73267327 \\
\hline Sampel 7 & 35,18019802 \\
\hline Sampel 8 & 51,29108911 \\
\hline Sampel 9 & 210,0237624 \\
\hline Sampel 10 & 145,6990099
\end{tabular}

Kadar kafein pada kopi robusta sangat fluktuatif dan tidak tergantung dengan tingkat kematangan, akan tetapi setiap informasi perubahan warna memiliki karakteristik kandungan kafein tersendiri dan tentunya akan menjadi database pada sensor warna sebagai penciri kopi robusta.

\section{KESIMPULAN DAN SARAN}

Karakterisasi sensor warna TC3200 sebagai pengukur kadar kafein telah berhasil dilakukan, dari hasil pengujian sensor dapat bekerja dengan baik pada tingkat kematangan hasil roasting kopi normal/tidak sangat matang.untuk peningkatan pengukuran perlu penambahan sample dengan variasi suhu roasting agar database sensor semakin lengkap dalam pengukuran kadar kafein.

\section{UCAPAN TERIMAKASIH}

Penelitian ini telah didanai melalui penelitian visi Fakultas Sains dan Teknologi Tahun 2021.

\section{DAFTAR PUSTAKA}

Arboleda, E. R., 2019. Comparing performances of data mining algorithms for classification of green coffee beans. Int. J. Eng. Adv. Technol, 8(5), 1563-1567.

Arwangga, A.F., Asih, I.A., Sudiarta, I.W. 2016. Analisis Kandungan Kafein Pada Kopi Di Desa Sesaot Narmada Menggunakan Spektrofotometri UV-Vis. Jurnal Kimia, 10 (1): 110-114.
Rosita, R., Budiastra, I.W., Sutrisno,. 2016. Prediksi Kafein Biji Kopi Arabika Gayo dengan Near Infrared Spektroscopy. JTEP Jurnal Keteknikan Pertanian, 4(2): 179-186.

Belay, A.,Ture, K., Redi, M., \& Aswaf, A. 2008. Measurement of caffeine in coffee beans with UV/vis spectrometer. Food Chemistry, 108 (2008); 310-315.

Craig, A. P., G. Bothelo., L. S. Oliveira., A. S. Franca,. 2018. Mid Infrared spectroscopy and chemometrics as tools for the classification of roasted coffees by cup quality. Food Chemistry, 245 (2018); 1052-1061.

Direktorat Jendral Perkebunan, 2019. Buku Statistik perkebunan. Kementerian Pertanian.

Farah, Adriana. Coffee :Emerging Health Effects and Disease Prevention, First Edition. John Willey \& Sons, Inc and Institute of Food Technologists (USA) : WileyBlackwell Publising Ltd; 2012.

Husni, M. L., Rasyad, S., Putra, M.S., Hasan, Y., Rasyid, J. A., 2020. Pengaplikasian Sensor Warna Pada Navigasi Line Tracking Robot Sampah Berbasis Mikrokontroler, Jurnal Ampere, 4 (2); 297.

Iwanto, Suryadi. D., Priyatman. P., 2018. Rancang Bangun Alat Pendeteksi Kadar Boraks Pada Makanan Menggunakan Sensor Warna TCS3200 Berbasis Arduino Uno R3, Jurnal Teknik Elektro Universitas Tanjungpura, 2 (1).

Jiang, H., W. Xu., Q. Chen., 2020. Determination of tea polyphenols in green tea by homemade color sensitive sensor combined with multivariate analysis. Food chemistry, 319 (2020); 126584.

Singgih, H., 2013. Uji Kandungan Formalin Pada Ikan Asin Menggunakan Sensor Warna Dengan Bantuan FMR (Formalin Main Reagent). Jurnal ELTEK, 11 (1); 1693-4024.

Syam, S., 2017. Prototipe Alat Ukur dan Rekam Kadar Hara Tanah Sawah Menggunakan Sensor Warna. Jurnal IT, 8 (3); 136-143.

Putra, A. E., Nugraha, R., Pangaribuan, P., Pendeteksi kemurnian bensin C8H18 Di SPBU Pertamina Berbasis Sensor Warna Portable. E-Proceeding of Enginerering, 4 (2); 1392-1401. 